\title{
1 FISSION YEAST CELL WALL ANALYSIS
}

2 Pilar Pérez* and Juan C. Ribas

3 Instituto de Biología Funcional y Genómica, Consejo Superior de Investigaciones Científicas /

4 Universidad de Salamanca. 37007 Salamanca, Spain.

5

6

7 Short tittle: cell wall analysis

8

9 Key words: cell wall; polysaccharides; $\beta$-glucan, $\alpha$-glucan; mannan, Bgs.

10 Abbreviations: B-BG, branched $\beta(1,3)$-glucan; CW, Calcofluor white; GS, glucan synthase; 11 IEM, Immunoelectron microscopy; L-BG, linear $\beta(1,3)$-glucan; TEM, Transmission electron 12 microscopy.

13

$14 *$ Corresponding author:

15 Phone: (34) 923-294894

16 Fax: (34) 923-224876

17 E-mail: piper@usal.es 


\section{Abstract}

2 Schizosaccharomyces pombe cell wall is a rigid exoskeletal structure mainly composed of 3 interlinked glucose polysaccharides and galactomannoproteins. It is essential for survival of the

4 fission yeast, prevents cells from bursting from the internal turgor pressure and protects them

5 from mechanical injuries. Additionally, the cell wall determines the cell shape and, therefore, a

6 better knowledge of the cell wall structure and composition could provide valuable data in $S$.

7 pombe morphogenetic studies. Here we provide information about this structure and the current

8 reliable methods for rapid analysis of the cell wall polymers by specific enzymatic and chemical

9 degradations of purified cell walls.

\section{I. Introduction}

12 The fission yeast cell wall represents around $20 \%$ of the cell dry weight. Although rigid, this

13 structure has some elasticity and is remodeled in a strictly regulated manner since it must adapt

14 to the environment and permit growth and the morphological changes that occur during the life

15 cycle. When observed by transmission electron microscopy, the $S$. pombe wall shows a three-

16 layer organization, with two electron-dense layers in the outer and inner sides, which are formed

17 mainly by galactomannoproteins representing $9-14 \%$ of total wall (Fig. 1A-D) (Horisberger et

18 al. 1978). The electron-transparent core layer is formed by $\alpha$-glucan (28-32\%) and three types of

$19 \quad \beta$-glucans: linear and branched $\beta(1,3)$-linked glucans $(50-54 \%)$ and $\beta(1,6)$-linked glucans, $(5-10$

$20 \%$ ) (Fig. 1F) (Manners and Meyer 1977; Humbel et al. 2001; Magnelli et al. 2002); Bush et al.

21 1974; Kopecka et al. 1995). These components form crystalline fibers that provide rigidity to

22 the cell wall (Sugawara et al. 2003). Budding yeast wall lacks linear $\beta(1,3)$-glucan and $\alpha(1,3)$ -

23 glucan polysaccharides and consists of branched $\beta(1,3)$ and $\beta(1,6)$-glucan, chitin, and

24 mannoproteins with no galactose residues (Lesage and Bussey 2006) (Orlean 2012).

\section{II. Molecular structure of fission yeast cell wall}

\section{1. $\beta$-glucans}

27 The $\beta$-glucans are polysaccharides composed of D-glucose monomers linked by $28 \beta(1,3)$ or $\beta(1,6)$ bonds. Traditionally, these $\beta$-glucans have been classified by the type of 
1 bonding of the main chain in two types: $\beta(1,3)$-glucan with branches attached via $\beta(1,6)$ bonds

2 (14\% of the total glucose) and $\beta(1,6)$ glucan with branches linked via $\beta(1,3)$ bonds $(75 \%$ of the

3 total glucose) (Bush et al. 1974; Manners and Meyer 1977). The $\beta(1,3)$-glucan is formed by two

4 types of glucans, linear $\beta(1,3)$-glucan (L-BG) and branched $\beta(1,3)$-glucan (B-BG) (Manners

5 and Meyer 1977; Humbel et al. 2001).

6 a) L-BG consists of $\beta$-(1,3)-linked glucose units forming linear chains arranged in a

7 conformation of single-helix with a small proportion of triple-helix structures (Saito et al. 1990;

8 Young and Jacobs 1998; Young et al. 2000; Cortés et al. 2007). It is the polysaccharide

9 responsible for the primary septum structure observed by electron microscopy (Fig. 1D, E and

10 G). This structure is similar to those found in plants, which is also formed by an L-BG named

11 callose (Verma and Hong 2001; Chen and Kim 2009), or in Saccharomyces cerevisiae, which is

12 formed by chitin. The single-helix conformation of L-BG makes the primary septum more

13 susceptible to degradation by $\beta(1,3)$-glucanases (Pelosi et al. 2003). L-BG is recognized with

14 higher affinity than the rest of $S$. pombe wall polysaccharides by the fluorochrome Calcofluor

15 White $(\mathrm{CW})$, and is responsible for the strong labeling of the septum with this compound

16 (Cortés et al. 2007).

17 b) $\underline{\mathbf{B}-\mathbf{B G}}$ is the most abundant cell wall polymer. It is made of $\beta(1,3)$-linked glucose units 18 forming linear chains with branching $\beta$-(1,6)-bound glucose units forming filamentous structures. Unlike L-BG, B-BG chains form closed triple-helix structures (Kopecka and Kreger

20 1986; Saito et al. 1990; Gawronski et al. 1999). Studies on protoplast cell wall regeneration 21 have shown that $\beta$-(1,3)-glucan polysaccharide is first deposited on the plasma membrane, 22 generating a network of microfibrils that extend to cover the whole surface; this network constitutes the frame on which the other polymers are deposited. As the protoplast grows, $\beta$ -

24 (1,3)-glucan allows the restoration of the initial cylindrical form of fission yeast (Osumi 1998; 25 Humbel et al. 2001). B-BG is essential for cell integrity and for secondary septum formation 26 (Fig. 1D and G). In addition, B-BG plays a crucial role in cytokinesis, linking the cell wall to 27 the plasma membrane and contractile actomyosin ring, which is needed to couple the septum 28 synthesis with the membrane and ring progression 
1 c) $\mathbf{\beta ( 1 , 6 ) - g l u c a n}$ is a highly branched polysaccharide formed by a main chain of $\beta(1,6)$-linked

2 glucose and $75 \%$ of $\beta(1,3)$-linked braches. This percentage of branches is much higher than that

3 of the $\beta(1,6)$-glucan of other yeasts like S. cerevisiae or Candida albicans. Because of the

4 abundance of both types of glucose links it is also called diglucan and represents $5-10 \%$ of the

5 wall (Sugawara et al. 2004; Magnelli et al. 2005; Lesage and Bussey 2006).

\section{$6 \quad$ 2. 2. $\underline{\alpha-g l u c a n}$}

7 This polysaccharide is absent in the budding yeast and in C. albicans, but is present in the wall 8 of filamentous and dimorphic fungi (Bush et al. 1974; Edwards et al. 2011). S. pombe $\alpha$-glucan 9 is a linear polysaccharide of approximately 260 glucose residues, formed by a tandem of two 10 linear chains, each consisting of about 120 residues of D-glucose bound by $\alpha-(1,3)$ linkages and $1110 \alpha-(1,4)$ linked residues (7\%) located at the reducing end of each chain (Grun et al. 2005). It 12 has an essential role in the maintenance of cell shape, as treatment with $\alpha$-glucanases in addition 13 to $\beta$-glucanases is required to produce round protoplasts (Alfa et al. 1993). Like B-BG, this 14 polysaccharide is essential for cell integrity and for secondary septum formation (Fig. 1D and 15 G)(Cortes et al. 2012; Muñoz et al. 2013). It also plays an essential role in the primary septum 16 adhesion strength needed to support the physical force of the internal turgor pressure during cell separation (Cortes et al. 2012).

\section{3. Galactomannan}

This polysaccharide is part of the cell wall glycoproteins covalently bound via $\mathrm{N}$ - and $\mathrm{O}$ glycosidic linkages. It consists of a linear backbone of $\alpha-(1,6)$ linked D-mannose units with branches formed by $\alpha(1,2)$ - or $\alpha(1,3)$-linked D-mannose and a terminal D-galactose residue in the non-reducing ends. A small amount of galactose not located at the terminal position has also been found (Bush et al. 1974; Horisberger et al. 1978). Most proteins found in the cell wall are water- or detergent-soluble and can be secreted to the medium. Few cell wall proteins are covalently linked to the polysaccharides and can be divided into two groups, proteins covalently attached to $\beta(1,3)$-glucan (Pir proteins) through a glutamine residue, an alkali-labile linkage that can be extracted by a mild alkali treatment; and proteins covalently attached by a GPI anchor to the $\beta(1,6)$-glucan that can be removed by glucanase treatment (de Groot et al. 2005; Ecker et al. 
1 2006; de Groot et al. 2007; Latge 2007; Klis et al. 2010; Latge 2010). S. pombe genome

2 contains 33 hypothetical GPI proteins (de Groot et al. 2003). Only two PIR-type proteins, with

3 alkali-sensitive bonds to the wall, have been described in S. pombe: Psu1, similar to proteins

4 belonging to S. cerevisiae SUN family; and Asl1, which is related to proteins from Aspergillus

5 fumigatus and Ustilago maydis (de Groot et al. 2007).

\section{$6 \quad$ 2.4. $\underline{\text { Cell wall organization }}$}

7 Analysis by scanning electron microscopy of wall regeneration in protoplasts showed that the

8 cell wall is initiated by creating a network of fibers, which in turn, are grouped into bundles

9 interconnected and surrounded by amorphous particles. $\beta-(1,3)$ glucan is the primary component

10 of the fiber structure (Osumi et al. 1998). However, $\alpha$-(1,3)-glucan is also required to form the

11 rigid structure, since mutants defective in the synthesis of $\alpha$-(1,3)-glucan, while maintaining the

12 fibrillar structure, are unable to develop shape (Horisberger and Rouvet-Vauthey 1985; Osumi

13 1998). Immunoelectron microscopy using colloidal gold-labeled lectins or antibodies specific

14 against galactomannan or different $\beta$-glucans respectively, have helped to define the

15 organization of the different polysaccharides in the S. pombe cell wall and septum (Fig. 1C-G)

16 (Horisberger and Rouvet-Vauthey 1985; Osumi 1998; Humbel et al. 2001). Lectins specifically

17 localize the galactomannan to the outer and inner sides of the cell wall (Fig. 1F). L-BG presents

18 an almost exclusive localization in primary septum (Humbel et al. 2001), although a small

19 amount is also observed in the cell wall (Cortés et al. 2007). B-BG is located in both primary

20 and secondary septum, as well as in the whole cell wall. Branched $\beta$-(1,6)-glucan forms a layer

21 in both the secondary septum and cell wall, closer to the outer surface of galactomannoproteins

22 (Fig. 1F) (Humbel et al. 2001). This would agree with the proposed function for $\beta$-(1,6)-glucan

23 connecting the exterior surface proteins with the remaining cell wall polysaccharides (Sugawara

24 et al. 2004). Although it has not been detected yet by immunoelectron microscopy, it is believed

25 that $\alpha$-(1,3)-glucan is localized with the B-BG in the less electron-dense region of the cell wall

26 and in both primary and secondary septum (Fig. 1F-G) (Cortes et al. 2012).

27 2.5. Cell wall biosynthetic and remodeling enzymes 
1 The biosynthesis of $\beta$-(1,3)-glucan is catalyzed by an enzyme complex well conserved in fungi

2 and plants called $\beta$-(1,3)-glucan synthase (GS) (EC 2.4.1.34, UDP-glucose:1,3- $\beta$-D-glucan 3- $\beta$ -

3 D-glucosyltransferase) which is associated to the inner side of the plasma membrane (Shematek

4 and Cabib 1980). This complex uses UDP-glucose as substrate, and in vitro synthesizes de novo

5 linear chains of 60-80 glucoses, which is a considerably smaller length compared to that of the

6 wall glucan chains. In all fungi and plants the GS complex is composed of at least two subunits:

7 an integral membrane protein corresponding to the catalytic subunit, and Rho1 GTPase, which

8 acts as the regulatory subunit (Arellano et al. 1996). The first GS catalytic subunit identified in

9 S. pombe was Cps1, later renamed Bgs1, which is very similar to the catalytic subunits of $S$.

10 cerevisiae (Ishiguro et al. 1997). ggsl $^{+}$was first cloned by complementation of the cps 1-12

11 mutant hypersensitive to a spindle poison (Ishiguro et al. 1997). Later, it was also isolated by

12 complementation of mutants defective in septum formation, and was involved in the Wee1-

13 dependent septation checkpoint (Le Goff et al. 1999; Liu et al. 2000b; Liu et al. 1999). Bgs1 is

14 responsible for the synthesis of the L-BG that forms the primary septum (Fig. 1E) (Cortés et al.

15 2007). Three more genes $b g s 2^{+}, b g s 3^{+}$and $b g s 4^{+}$have been found in the $S$. pombe genome.

16 bgs $2^{+}$expression is induced during sporulation. Bgs2 localizes to the ascospore periphery and is

17 required for ascospore wall maturation and survival (Liu et al. 2000a; Martin et al. 2000). Bgs3

18 and Bgs4, are like Bgs1, essential in vegetative cells and localized to the growing poles and

19 septum (Cortés et al. 2002; Liu et al. 2002; Martín et al. 2003; Cortés et al. 2005). The role of

20 Bgs3 is currently unknown. Genetics studies have shown that $b g 4^{+}, c w g 1^{+}$, orbl1 ${ }^{+}$, and $p b r 1^{+}$

21 are the same gen. Bgs4 is essential and its depletion promotes cell lysis mainly at the cell

22 separation onset. Bgs4 is responsible for B-BG synthesis, the major GS activity and the in vivo

23 and in vitro resistances to specific GS antifungal drugs (Ribas et al. 1991; Castro et al. 1995;

24 Cortés et al. 2005; Martins et al. 2011).

25 Ags1, also named Mok1, is a putative $\alpha$-glucan synthase whose activity has not been detected in vitro. Ags1 is essential for cell integrity (Hoschstenbach et al. 1998; Katayama et al. 1999).

27 Ags1 is detected in dividing and growing areas and confers the essential septum strength needed

28 for proper cell abscission (Katayama et al. 1999; Cortes et al. 2012). S. pombe contains four 
1 additional $a g s l^{+}$paralogues $\left(m o k 11^{+}-m o k 14^{+}\right)$, which are induced during sexual differentiation

2 (García et al. 2006).

3 Although the biosynthetic enzymes of the main polymers have been described, a comprehensive

4 understanding of the interactions between $S$. pombe cell wall components is still missing. The

5 L-BG, B-BG, or $\alpha(1,3)$-glucan synthesized remain disorganized until they are cross-linked to

6 other polysaccharides and proteins. Four of the fission yeast GPI proteins (Gas1, Gas2, Gas4,

7 and Gas5) are $\beta(1,3)$-glucanosyl-transferases related to $S$. cerevisiae Gas1, which is involved in

8 the maturation and branching of $\beta(1,3)$-glucan, and therefore is essential for the cell wall

9 assembly and proper maintenance of the cell. S. pombe Gas1 is essential during vegetative

10 growth and Gas4 during sporulation. Gas2 and Gas5 seem to play a minor role in cell wall

11 construction (de Medina-Redondo et al. 2008; de Medina-Redondo et al. 2010).

12

13 III. Choosing an appropriate protocol for cell wall analysis

15 Different methods can be used to detect the cell wall structure or composition. Some of them do 16 not need precise polymer quantification. Among them, those more commonly used are briefly 17 described below.

18 3.1. Non-quantitative methods for analysis of cell wall polysaccharides

$19 \quad 3.1 .1$. Electron microscopy

20 These techniques are numerous including A) Transmission electron microscopy (TEM) that 21 allows observation of the three-layered cell wall structure with different electron densities 22 (Figure 1A-D) (Osumi et al. 1998). B) Scanning electron microscopic (SEM), useful to observe 23 the cell surface with high fidelity (Osumi et al. 1995). This technique can be coupled with 24 lectins to detect a cell wall surface completely filled with particles specific for the mannan carbohydrate of glycoproteins (Osumi et al. 1995). C) Atomic force microscopy (AMF), used to measure the mechanical properties of the cell wall macromolecules (Dufrene 2010). D)

27 Cryoscanning and cryosectioning electron microscopy, useful to analyze fractured and coated 28 cell samples, allowing the observation of the ultrastructure of both external and internal cell 
1 components (Osumi et al. 2006). E) Immunoelectron microscopy (IEM) which uses specific

2 lectins or antibodies in combination with secondary antibodies conjugated to colloidal gold

3 particles to locate the different types of polysaccharides in the septum and cell wall structures

4 (Figure 1E) (Humbel et al. 2001).

$5 \quad$ 3.1.2. Microscopy with specific fluorochrome

6 Direct observation of living cells is an important method for cell wall studies. Fluorochromes

7 and fluorescence-conjugated lectins can be used for cell wall fluorescence microscopy analysis.

8 The most commonly used are: Calcofluor white (CW), also called Blankophor (Blankophor

$9 \mathrm{GmbH} \&$ Co.) or Fluorescent Brightener 28 (Sigma-Aldrich), which specifically stains the cell

10 wall L-BG; Concanavalin A, a lectin that binds mannose residues; lectin from Bandeiraea

11 simplicifolia, which recognizes specifically terminal galactose residues; and wheat germ

12 agglutinin (WGA), which recognizes $\mathrm{N}$-acetylglucosamine residues from glycoproteins (since

13 there is no chitin in S. pombe).

$14 \quad$ 3.1.3. Cell Sensitivity to enzymatic degradations or to cell wall synthesis inhibitors

15 This method can be used when alteration of the cell wall is suspected. It provides a rough

16 estimate of the cell wall state (Calonge et al. 2000; Martins et al. 2011). It can also be used in

17 screenings for mutations affecting the cell wall. Enzymatic complexes degrading $\beta$-glucans

18 (Zymolyase, Kitalase) or the entire cell wall (Glucanex) are used. Cell wall synthesis inhibitors

19 such as Calcofluor white, 2-deoxi-D-glucose, echinocandins (caspofungin, micafungin,

20 anidulafungin, pneumocandin or aculeacin), papulacandins or acidic terpenoids (enfumafungin)

21 are also used (Martins et al. 2011).

$22 \quad 3.1 .4$. Analysis of cell wall proteins

23 The SDS-soluble cell wall proteins are extracted by hot $2 \%$ SDS-40 mM mercaptoethanol 24 treatment $\left(15 \mathrm{~min} 100^{\circ} \mathrm{C}\right)$ and concentrated by cold acetone precipitation. The proteins covalently attached to $\beta(1,3)$-glucan can be purified by treatment with $30 \mathrm{mM} \mathrm{NaOH}$ at $4^{\circ} \mathrm{C}$ for $16 \mathrm{~h}$. The GPI attached proteins are released by degradation of the GPI anchor by treatment with undiluted pyridine hydrofluoride at $24^{\circ} \mathrm{C}$ for $16 \mathrm{~h}$. Both groups of covalently attached proteins

28 can be released by treatment with recombinant endo- $\beta(1,3)$-glucanase. Then, the proteins are 
1 analyzed by SDS-PAGE or Western blot. As wall glycoproteins are heavily glycosylated and

2 this may interfere with the electrophoresis analysis, the $\mathrm{N}$-linked oligosaccharides can be

3 removed by treatment with endoglycosidase $\mathrm{H}$. Additionally, the cell wall proteins can be

4 biotin-labeled directly in the cell prior to cell wall purification, and visualized in the Western

5 blot with streptavidin-horseradish peroxidase conjugate (Mrsa et al. 1997; Mrsa and Tanner

$6 \quad 1999)$.

7 Galactomannan can be specifically analyzed by incorporation of radioactive orthophosphate into

8 N-mannosylated glycoproteins. The phosphate is bound as mannose-6-phosphate to both SDS-

9 soluble and covalently linked cell wall mannoproteins. The phosphorylated cell wall

10 oligosaccharides can be characterized after hydrolysis in trifluoroacetic acid by Quaternary

11 aminoethyl (QAE)-Sephadex A50 chromatography, Bio-Gel P2 chromatography, high-

12 performance anionic-exchange chromatography (HPAEC), electrospray ionization tandem mass

13 spectrometry (ESI-MS-MS), and methylation analysis with gas chromatography-mass

14 spectrometry (Mrsa et al. 1999).

\section{3.2. Radioactive labeling and quantitative analysis of cell wall polysaccharides}

16 Different methods can be used to analyze the cell wall polysaccharide composition. All of them require a separation of the wall from the rest of cell components. Some methods consist of combinations of chemical degradations and analytical techniques that permit the determination of the degradation products. These methods usually require more effort but provide information about the type of bonds between the monosaccharides forming the polymers. Common chemical degradations include alkali solubilization, acid hydrolysis, periodate oxidation, Smith degradation, borohydride reduction, $\beta$-elimination, carboxymethylation, and permethylation.

23 Common analytical techniques include determination of reducing sugars, of total sugars, of 24 glucose, of glucosamine, methylation analysis, gas-liquid chromatography, mass spectrometry, paper chromatography, gel filtration (size-exclusion) chromatography, thin-layer chromatography (TLC), affinity chromatography, high-performance ion-exchange

27 chromatography (HPLC and HPAEC), nuclear magnetic resonance (NMR) spectroscopy, X-ray

28 diffraction, and pulse amperometry (Manners et al. 1973a; Manners et al. 1973b; Bush et al. 
1974; Manners and Meyer 1977; Sietsma and Wessels 1977; Gopal et al. 1984; Montijn et al.

1994; Kollar et al. 1995; Kollar et al. 1997; Fontaine et al. 2000; Magnelli et al. 2002; Sugawara

et al. 2003; Sugawara et al. 2004; Cabib and Durán 2005; Magnelli et al. 2005; Francois 2006).

The current method has been adapted for a simple, accurate and rapid analysis of wall polysaccharides based on ${ }^{14} \mathrm{C}$-glucose labeling and fractionation of cell wall polysaccharides using specific chemical and enzymatic procedures.

\section{ACKNOWLEDGEMENTS}

We thank D. Posner for language revision. This work was supported by grants BFU2010-15641 and BIO2012-35372 from the Dirección General de Investigación, MICINN, Spain, and grants CSI038A11-2 and CSI376A12-2 from the Junta de Castilla y León, Spain.

\section{BIBLIOGRAPHY}

Alfa C, Fantes P, Hyams J, McLeod M, Warbrick E, ed. 1993. Experiments with fission yeast: a laboratory course manual. Cold Spring Harbor Laboratory Press, Cold Spring Harbor, N.Y.

Arellano M, Duran A, Perez P. 1996. Rho1 GTPase activates the (1-3) $\beta$-D-glucan synthase and is involved in Schizosaccharomyces pombe morphogenesis. EMBO J 15: 4584-4591.

Bush DA, Horisberger M, Horman I, Wursch P. 1974. The wall structure of Schizosaccharomyces pombe. J Gen Microbiol 81: 199-206.

Cabib E, Durán A. 2005. Synthase III-dependent chitin is bound to different acceptors depending on location on the cell wall of budding yeast. J Biol Chem 280: 91709179.

Calonge TM, Nakano K, Arellano M, Arai R, Katayama S, Toda T, Mabuchi I, Pérez P. 2000. Schizosaccharomyces pombe rho2p GTPase regulates cell wall $\alpha$-glucan biosynthesis through the protein kinase pck2p. Mol Biol Cell 11: 4393-4401.

Castro C, Ribas JC, Valdivieso MH, Varona R, del Rey F, Durán A. 1995. Papulacandin $\mathrm{B}$ resistance in budding and fission yeasts: isolation and characterization of a gene involved in $(1,3) \beta$-D-glucan synthesis in Saccharomyces cerevisiae. $J$ Bacteriol 177: 5732-5739.

Cortés JC, Konomi M, Martins IM, Munoz J, Moreno MB, Osumi M, Durán A, Ribas JC. 2007. The $(1,3) \beta$-D-glucan synthase subunit Bgs1p is responsible for the fission yeast primary septum formation. Mol Microbiol 65: 201-217.

Cortés JC, Sato M, Munoz J, Moreno MB, Clemente-Ramos JA, Ramos M, Okada H, Osumi M, Duran A, Ribas JC. 2012. Fission yeast Ags1 confers the essential septum strength needed for safe gradual cell abscission. J Cell Biol 198: 637656. 
Cortés JCG, Carnero E, Ishiguro J, Sánchez Y, Durán A, Ribas JC. 2005. The novel fission yeast $(1,3) \beta$-D-glucan synthase catalytic subunit Bgs $4 p$ is essential during both cytokinesis and polarized growth. J Cell Sci 118: 157-174.

Cortés JCG, Ishiguro J, Durán A, Ribas JC. 2002. Localization of the $(1,3) \beta$-D-glucan synthase catalytic subunit homologue Bgs1p/Cps1p from fission yeast suggests that it is involved in septation, polarized growth, mating, spore wall formation and spore germination. J Cell Sci 115: 4081-4096.

Chen XY, Kim JY. 2009. Callose synthesis in higher plants. Plant signal behav 4: 489492.

de Groot PW, Hellingwerf KJ, Klis FM. 2003. Genome-wide identification of fungal GPI proteins. Yeast 20: 781-796.

de Groot PW, Ram AF, Klis FM. 2005. Features and functions of covalently linked proteins in fungal cell walls. Fungal Genet Biol 42: 657-675.

de Groot PW, Yin QY, Weig M, Sosinska GJ, Klis FM, de Koster CG. 2007. Mass spectrometric identification of covalently bound cell wall proteins from the fission yeast Schizosaccharomyces pombe. Yeast 24: 267-278.

de Medina-Redondo M, Arnaiz-Pita Y, Clavaud C, Fontaine T, del Rey F, Latge JP, Vazquez de Aldana CR. 2010. $\beta(1,3)$-glucanosyl-transferase activity is essential for cell wall integrity and viability of Schizosaccharomyces pombe. PloS one 5: e14046.

de Medina-Redondo M, Arnaiz-Pita Y, Fontaine T, Del Rey F, Latge JP, Vazquez de Aldana CR. 2008. The $\beta$-1,3-glucanosyltransferase gas4p is essential for ascospore wall maturation and spore viability in Schizosaccharomyces pombe. Mol Microbiol 68: 1283-1299.

Dufrene YF. 2010. Atomic force microscopy of fungal cell walls: an update. Yeast 27: 465-471.

Ecker M, Deutzmann R, Lehle L, Mrsa V, Tanner W. 2006. Pir proteins of Saccharomyces cerevisiae are attached to $\beta$-1,3-glucan by a new proteincarbohydrate linkage. J Biol Chem 281: 11523-11529.

Edwards JA, Alore EA, Rappleye CA. 2011. The yeast-phase virulence requirement for alpha-glucan synthase differs among Histoplasma capsulatum chemotypes. Eukaryotic cell 10: 87-97.

Fontaine T, Simenel C, Dubreucq G, Adam O, Delepierre M, Lemoine J, Vorgias CE, Diaquin M, Latge JP. 2000. Molecular organization of the alkali-insoluble fraction of Aspergillus fumigatus cell wall. J Biol Chem 275: 27594-27607.

Francois JM. 2006. A simple method for quantitative determination of polysaccharides in fungal cell walls. Nature protocols 1: 2995-3000.

García I, Tajadura V, Martín V, Toda T, Sánchez Y. 2006. Synthesis of $\alpha$-glucans in fission yeast spores is carried out by three $\alpha$-glucan synthase paralogues, Mok12p, Mok13p and Mok14p. Mol Microbiol 59: 836-853.

Gawronski M, Park JT, Magee AS, Conrad H. 1999. Microfibrillar structure of PGGglucan in aqueous solution as triple-helix aggregates by small angle $\mathrm{x}$-ray scattering. Biopolymers 50: 569-578.

Gopal PK, Shepherd MG, Sullivan PA. 1984. Analysis of wall glucans from yeast, hyphal and germ-tube forming cells of Candida albicans. J Gen Microbiol 130: 3295-3301.

Grun CH, Hochstenbach F, Humbel BM, Verkleij AJ, Sietsma JH, Klis FM, Kamerling JP, Vliegenthart JF. 2005. The structure of cell wall $\alpha$-glucan from fission yeast. Glycobiology 15: 245-257. 
Horisberger M, Rouvet-Vauthey M. 1985. Cell wall architecture of the fisson yeast Schizosaccharomyces pombe. Experientia 41: 748-750.

Horisberger M, Vonlanthen M, Rosset J. 1978. Localization of $\alpha$-galactomannan and of wheat germ agglutinin receptors in Schizosaccharomyces pombe. Arch Microbiol 119: 107-111.

Hoschstenbach F, Klis FM, Van den Ende H, Van Donselaar E, Peters PJ, Klausner RD. 1998. Identification of a putative alpha-glucan synthase essential for cell wall construction and morphogenesis in fission yeast. Proc Natl Acad Sci USA 95: 9161-9166.

Humbel BM, Konomi M, Takagi T, Kamasawa N, Ishijima SA, Osumi M. 2001. In situ localization of $\beta$-glucans in the cell wall of Schizosaccharomyces pombe. Yeast 18: 433-444.

Ishiguro J, Saitou A, Durán A, Ribas JC. 1997. cps $1^{+}$, a Schizosaccharomyces pombe gene homolog of Saccharomyces cerevisiae FKS genes whose mutation confers hypersensitivity to cyclosporin A and papulacandin B. J Bacteriol 179: 76537662.

Katayama S, Hirata D, Arellano M, Pérez P, Toda T. 1999. Fission yeast $\alpha$-glucan synthase Mok1 requires the actin cytoskeleton to localize the sites of growth and plays an essential role in cell morphogenesis downstream of protein kinase $\mathrm{C}$ function. J Cell Biol 144: 1173-1186.

Klis FM, Brul S, De Groot PW. 2010. Covalently linked wall proteins in ascomycetous fungi. Yeast 27: 489-493.

Kollar R, Petrakova E, Ashwell G, Robbins PW, Cabib E. 1995. Architecture of the yeast cell wall. The linkage between chitin and $\beta(1-3)$-glucan. J Biol Chem 270: 1170-1178.

Kollar R, Reinhold BB, Petráková E, Yeh HJ, Ashwell G, Drgonová J, Kapteyn JC, Klis FM, Cabib E. 1997. Architecture of the yeast cell wall. $\beta(1-6)$-glucan interconnects mannoprotein, $\beta(1-3)$-glucan, and chitin. J Biol Chem 272: 1776217775.

Kopecka M, Kreger DR. 1986. Assembly of microfibrils in vivo and in vitro from (1-3)$\beta$-D-glucan synthesized by protoplasts of Saccharomyces cerevisiae. Arch Microbiol 143: 387-395.

Latge JP. 2007. The cell wall: a carbohydrate armour for the fungal cell. Mol Microbiol 66: $279-290$.

Latge JP. 2010. Tasting the fungal cell wall. Cell Microbiol 12: 863-872.

Lesage G, Bussey H. 2006. Cell wall assembly in Saccharomyces cerevisiae. Microbiol Mol Biol Rev 70: 317-343.

Liu J, Tang X, Wang H, Oliferenko S, Balasubramanian MK. 2002. The localization of the integral membrane protein Cps1p to the cell division site is dependent on the actomyosin ring and the septation-inducing network in Schizosaccharomyces pombe. Mol Biol Cell 13: 989-1000.

Magnelli P, Cipollo JF, Abeijon C. 2002. A refined method for the determination of Saccharomyces cerevisiae cell wall composition and $\beta$-1,6-glucan fine structure. Anal Biochem 301: 136-150.

Magnelli PE, Cipollo JF, Robbins PW. 2005. A glucanase-driven fractionation allows redefinition of Schizosaccharomyces pombe cell wall composition and structure: assignment of diglucan. Anal Biochem 336: 202-212.

Manners DJ, Masson AJ, Patterson JC. 1973a. The structure of a $\beta$-(1-3)-D-glucan from yeast cell walls. Biochem J 135: 19-30. 
Manners DJ, Masson AJ, Patterson JC, Bjorndal H, Lindberg B. 1973b. The structure of a $\beta$-(1-6)-D-glucan from yeast cell walls. Biochem J 135: 31-36.

Manners DJ, Meyer MT. 1977. The molecular structures of some glucans from the cell walls of Schizosaccharomyces pombe. Carbohydr Res 57: 189-203.

Martín V, García B, Carnero E, Durán A, Sánchez Y. 2003. Bgs3p, a putative 1,3- $\beta$ glucan synthase subunit, is required for cell wall assembly in Schizosaccharomyces pombe. Eukaryot Cell 2: 159-169.

Martins IM, Cortés JCG, Muñoz J, Moreno MB, Ramos M, Clemente-Ramos JA, Durán A, Ribas JC. 2011. Differential activities of three families of specific $\beta(1,3)$ glucan synthase inhibitors in wild-type and resistant strains of fission yeast. J Biol Chem 286: 3484-3496.

Montijn RC, van Rinsum J, van Schagen FA, Klis FM. 1994. Glucomannoproteins in the cell wall of Saccharomyces cerevisiae contain a novel type of carbohydrate side chain. J Biol Chem 269: 19338-19342.

Mrsa V, Ecker M, Strahl-Bolsinger S, Nimtz M, Lehle L, Tanner W. 1999. Deletion of new covalently linked cell wall glycoproteins alters the electrophoretic mobility of phosphorylated wall components of Saccharomyces cerevisiae. J Bacteriol 181: 3076-3086.

Mrsa V, Seidl T, Gentzsch M, Tanner W. 1997. Specific labelling of cell wall proteins by biotinylation. Identification of four covalently linked O-mannosylated proteins of Saccharomyces cerevisiae. Yeast 13: 1145-1154.

Mrsa V, Tanner W. 1999. Role of NaOH-extractable cell wall proteins Ccw5p, Ccw6p, Ccw7p and Ccw8p (members of the Pir protein family) in stability of the Saccharomyces cerevisiae cell wall. Yeast 15: 813-820.

Muñoz J, Cortes JC, Sipiczki M, Ramos M, Clemente-Ramos JA, Moreno MB, Martins IM, Perez P, Ribas JC. 2013. Extracellular cell wall beta(1,3)glucan is required to couple septation to actomyosin ring contraction. J Cell Biol 203: 265-282.

Orlean P. 2012. Architecture and biosynthesis of the Saccharomyces cerevisiae cell wall. Genetics 192: 775-818.

Osumi M. 1998. The ultrastructure of yeast: cell wall structure and formation. Micron 29: 207-233.

Osumi M, Konomi M, Sugawara T, Takagi T, Baba M. 2006. High-pressure freezing is a powerful tool for visualization of Schizosaccharomyces pombe cells: ultra-low temperature and low-voltage scanning electron microscopy and immunoelectron microscopy. J Electron Microsc (Tokyo) 55: 75-88.

Osumi M, Sato M, Ishijima SA, Konomi M, Takagi T, Yaguchi H. 1998. Dynamics of cell wall formation in fission yeast, Schizosaccharomyces pombe. Fungal Genet Biol 24: 178-206.

Osumi M, Yamada N, Yaguchi H, Kobori H, Nagatani T, Sato M. 1995. Ultrahighresolution low-voltage SEM reveals ultrastructure of the glucan network formation from fission yeast protoplast. J Electron Microsc (Tokyo) 44: 198206.

Pelosi L, Imai T, Chanzy H, Heux L, Buhler E, Bulone V. 2003. Structural and morphological diversity of (1-3)- $\beta$-D-glucans synthesized in vitro by enzymes from Saprolegnia monoica. Comparison with a corresponding in vitro product from blackberry (Rubus fruticosus). Biochemistry 42: 6264-6274.

Ribas JC, Díaz M, Durán A, Pérez P. 1991. Isolation and characterization of Schizosaccharomyces pombe mutants defective in cell wall (1-3) $\beta$-D-glucan. $J$ Bacteriol 173: 3456-3462. 

SS, secondary septum. 701. 310: 91-99.

\section{FIGURE LEGEND}

Saito H, Yoshioka Y, Yoloi M, Yamada J. 1990. Distinct gelation mechanism between linear and branched (1-3)- $\beta$-D-glucans as revealed by high resolution solid state ${ }^{13}$ C NMR. Biopolymers 29: 1689-1698.

Shematek EM, Cabib E. 1980. Biosynthesis of yeast cell wall. II. Regulation of $\beta(1-$ 3)glucan synthetase by ATP and GTP. J Biol Chem 255: 895-902.

Sietsma JH, Wessels JG. 1977. Chemical analysis of the hyphal wall of Schizophyllum commune. Biochim Biophys Acta 496: 225-239.

Sugawara T, Sato M, Takagi T, Kamasaki T, Ohno N, Osumi M. 2003. In situ localization of cell wall $\alpha-1,3$-glucan in the fission yeast Schizosaccharomyces pombe. J Electron Microsc (Tokyo) 52: 237-242.

Sugawara T, Takahashi S, Osumi M, Ohno N. 2004. Refinement of the structures of cell-wall glucans of Schizosaccharomyces pombe by chemical modification and NMR spectroscopy. Carbohydr Res 339: 2255-2265.

Verma DP, Hong Z. 2001. Plant callose synthase complexes. Plant Mol Biol 47: 693-

Young SH, Dong WJ, Jacobs RR. 2000. Observation of a partially opened triple-helix conformation in 1-3- $\beta$-glucan by fluorescence resonance energy transfer spectroscopy. J Biol Chem 275: 11874-11879.

Young SH, Jacobs RR. 1998. Sodium hydroxide-induced conformational change in schizophyllan detected by the fluorescence dye, aniline blue. Carbohydr Res

Figure 1. (A,B,C,D) TEM images of the fission yeast. Whole cells (A and B); details of the three-layered cell wall (C), and the septum (D) are shown. Images originally published in J. Cell Biol. 198: 637-656 (Cortes et al., 2012). (E) IEM showing L-BG distribution in the primary septum. Image originally published in Mol Microbiol 65: 201-217 (Cortes et al., 2007). F) Scheme of the cell wall organization. G) Scheme of the septum. PS, primary septum; 

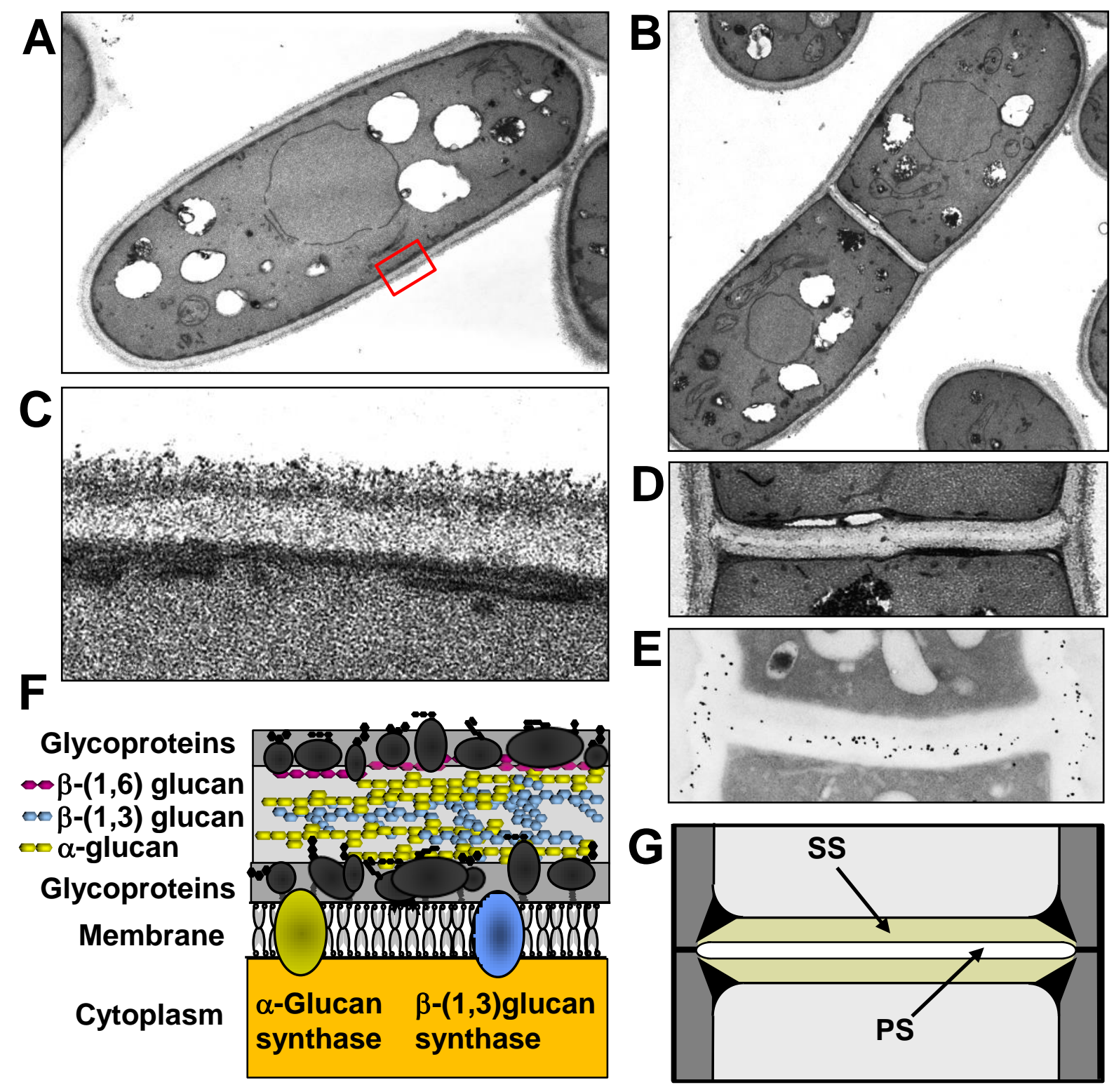